\title{
Neuropatia óptica isquêmica após anestesia geral em paciente idoso
}

- Yara Marcondes M. Castiglia

- Fábio Ferrari

- Sammy Mendes do Nascimento

\author{
CET-SBA, Departamento de Anestesiologia da Faculdade de Medicina \\ da Universidade Estadual Paulista, Botucatu, São Paulo
}

INTRODUCॄÃa

É de $0,05 \%$ a $1 \%$ a perda de visão pós-operatória (PVP). Descreve-se um caso após prostatectomia radical sob anestesia geral inalatória.

RELATO DO CASD

Paciente masculino, 72 anos, $85 \mathrm{~kg}, 1,70 \mathrm{~m}$, neoplasia de próstata. Bom estado geral, diabetes mellitus tipo 2 (10 a) e neuropatia periférica. Pressão arterial (PA) de $140 / 80 \mathrm{mmHg}$, freqüência cardíaca de 66 bpm, ASA III, ECG e RX de tórax normais. Hematócrito $(\mathrm{Ht})=38,8 \%$ e hemoglobina $(\mathrm{Hb})=13,2 \mathrm{~g} \%$. Monitorização com cardioscópio (rítmico), oximetria de pulso $\left(\mathrm{SpO}_{2}=94 \%\right)$, PA não-invasiva $(160 / 98 \mathrm{mmHg})$, pressão venosa central e capnografia pós-intubação. Indução anestésica com sufentanil, etomidato e atracúrio e intubação, sem intercorrências. Manutenção com sufentanil contínuo, isoflurano e $\mathrm{N}_{2} \mathrm{O} / \mathrm{O}_{2}$ $(50 \%)$. Após $10 \mathrm{~min}$ da indução, hipotensão que respondeu à efedrina venosa. Outros episódios, após sangramentos, responderam à efedrina e/ou diminuição dos inalatórios e opióide. Administraram-se três concentrados de hemácias $(\mathrm{CH})$ e total de $6.500 \mathrm{~mL}$ de Ringer com lactato (RL). Tramadol, dipirona e ondansetron, venosa, no final da anestesia, que durou $375 \mathrm{~min}$. $\mathrm{Ht}$ final de 36,4\%, e Hb de 12,7 g\%, glicemia (G) de $160 \mathrm{mg} \%$, sem outras alteraçôes. $\mathrm{O}$ paciente foi então encaminhado à sala de recuperação pós-anestésica (SRPA) com PA = 180/80 mmHg, extubado, recebendo $\mathrm{O}_{2}$ sob máscara $\left(\mathrm{SpO}_{2} ; 98 \%\right)$. Após 80 min, hipotensão sem resposta à Trendelenburg; maior hidratação e efe- drina. Transfusão de $2 \mathrm{CH}$ e dopamina, dose $\beta$ e, depois $\alpha$, com PA de 100/60 mmHg. Suspeita de insuficiência adrenal aguda e hidrocortisona venosa não alterou PA. Episódios de vômitos, sudorese fria, palidez e glicemia entre 200 e 300 mg\%. Realizados ECG (normal) e dosagens de CPK e CKMB (aumentadas, com troponina normal). Alta após $340 \mathrm{~min}$ na SRPA, com dopamina $-\mathrm{PA}=100 / 60 \mathrm{mmHg}-$, sem anemia. Na enfermaria, na admissão e no primeiro pós-operatório, houve queixa de visão embaçada, que piorou no segundo PO e evoluiu para PVP. A avaliação oftalmológica identificou alterações retinianas típicas de vasculopatia diabética: microaneurismas, hemorragias e exsudatos duros. A avaliação neurológica, no terceiro PO, diagnosticou neuropatia óptica isquêmica anterior (NOIA).

DISCUSSÃa

A NOIA é a principal causa de PVP, comum em idosos, mais predispostos à aterosclerose, que altera a auto-regulação do fluxo sanguíneo do nervo óptico. Os fatores precipitantes são hipotensão prolongada, anemia e transfusões maciças.

1. Katzman SS, et al. Spine. 1994;19:289-95.

REFERÊNCIA

Endereço para correspondência:

Francisco Sobreira G. Júnior

Distrito de Rubião Júnior - Caixa Postal 530

Botucatu (SP) - CEP 18618-970 